\title{
Procedimiento monitorio hondureño desde el derecho procesal comparado europeo. Garantía constitucional del derecho a la defensa
}

\author{
Rafael Andree Salgado Mejía ${ }^{1}$ \\ César Andrés Velásquez Moncada ${ }^{2}$
}

\section{RESUMEN}

El objetivo de este proyecto de tesis es crear un instrumento de consulta que permita una mejor comprensión a los usuarios sobre un nuevo procedimiento para la reclamación de deudas dinerarias, de origen europeo adaptado al Código Procesal Civil hondureño, denominado proceso monitorio, cuyas fuentes están en el estudio del derecho procesal comparado europeo, con relación al hondureño, específicamente en el estudio de legislaciones como la alemana, española, francesa e italiana, ya que en estos países surgió este mecanismo y es donde ha evolucionado, de tal manera que varios países del mundo lo han adoptado por su eficacia. Asimismo, se pretende determinar si mediante la ejecución derivada de la inacción del deudor se violentan las garantías procesales del mismo. Esta investigación es de tipo histórico y documental, por lo cual conlleva el conocimiento de los antecedentes históricos y aspectos doctrinales del proceso monitorio a través de la revisión documental de resoluciones, códigos de procedimientos civiles europeos, leyes sustantivas aplicables, revistas jurídicas, tratados, libros de derecho y demás documentos de utilidad.

Palabras clave: derecho procesal, derecho comparado, proceso monitorio, derecho a la defensa, ley de enjuiciamiento civil español, código procesal civil hondureño, código de procedimiento civil alemán, código de procedimiento civil italiano, código de procedimientos civil francés.

\section{ABSTRACT}

The aim of this thesis project is to create a reference tool, to provide a better understanding on a new procedure for claiming pecuniary claims of European origin adapted to Honduran Civil Procedure Code, the Monitoring process, whose sources are obtained by studying the European Compared Litigation in relation to Honduras. Specifically the study of law as the German, Spanish, French and Italian as in these

\footnotetext{
${ }^{1}$ Estudiante, Carrera de Derecho, UNAH-VS, dirección electrónica: rasmsr@hotmail.com

${ }^{2}$ Asesor, Carrera de Derecho, UNAH-VS, dirección electrónica: anvemo_64@hotmail.com
} 
countries was where this mechanism emerged and where it has evolved to the point that several countries of the world have adopted it for their effectiveness. In turn determine, if through the execution derived from the inaction of the debtor are violate the procedural guarantees of same. This research is historical and documentary type, involves knowing the historical and doctrinal aspects of the Monitoring process through documentary review of resolutions, European civil procedure codes, applicable substantive law, legal periodicals, treatises, law books, and other written and recorded documents that are useful.

Keywords: Litigation, Comparative Law, Monitoring process, Right to Defense, Spanish Civil Procedure Law, Honduran Civil Procedure Code, German Civil Procedure Code, Italian Civil Procedure Code, French Civil Procedure Code.

\section{INTRODUCCIÓN}

Al reformarse el proceso civil hondureño, derogándose el Código de Procedimientos Civiles del 8 de febrero de 1906 e introduciendo el Código Procesal Civil de Honduras (CPCH) en el derecho positivo hondureño, según Decreto número 211-2006, se dio apertura a los juicios orales en materia civil, dejando el formalismo excesivo del proceso escrito para entrar a lo que es la oralidad, en la cual el juzgador deja de ser un simple signatario de escritos y empieza a tomar la conducción de un verdadero juicio oral.

En este contexto, este trabajo pretende explicar un nuevo procedimiento incluido en dicho cuerpo legal, regulado en el título V, capítulo único, artículos 676 al 685 del $\mathrm{CPCH}$, al procedimiento monitorio, ya que si bien es una novedad en la legislación hondureña, también lo han sido las diferentes instituciones del derecho procesal civil que rigen la vida del actual proceso civil hondureño.

Este mecanismo es efectivo, ya que permite a los ciudadanos y a la justicia una alternativa al procedimiento ordinario para obtener un título ejecutivo y proceder a su ejecución. Lo anterior se puede ilustrar al consultar el proceso monitorio ${ }^{3}$ uniforme para Europa, denominado Libro verde sobre proceso monitorio, cuya consulta está abierta a todos los interesados dentro de la Unión Europea, el cual brinda un mejor entendimiento de este proceso.

${ }^{3}$ El Libro Verde tiene por objeto iniciar una consulta con todas las partes interesadas sobre posibles medidas que deben tomarse a nivel comunitario europeo para crear un proceso monitorio europeo, basándose en un estudio comparativo de la manera en que los Estados miembros tratan actualmente los correspondientes problemas procesales. 
Este mecanismo nació en Italia. Por su novedad y eficacia desde su aparición pronto se expandió por Europa, principalmente en Alemania y Francia, hasta llegar al continente americano, siendo Uruguay el primer país en introducirlo, en 1989, en su código general del proceso vigente; asimismo lo hizo Costa Rica, en Centroamérica.

En Honduras, con pocos años de experiencia monitoria, se puede apreciar en los tribunales de justicia civiles la falta de pericia sobre el mismo, tal es el caso de las demandas presentadas cuya pretensión es hacer valer un crédito por la vía monitoria, valiéndose nada más de la cuantía exigida por la ley; ${ }^{4}$ cuando perfectamente podrían accionar mediante un juicio ejecutivo o interponiendo demandas por la vía ordinaria ignorando este nuevo mecanismo; por tal razón, el objetivo de esta investigación es crear un instrumento de consulta que permita a estudiantes y profesionales del Derecho una mejor compresión del tema, igualmente brindar información sobre su origen, alcance, finalidad, formas y demás generalidades. También se aborda la crítica que hacen algunos doctrinarios con respecto a la garantía constitucional del derecho a la defensa en los casos de falta de oposición.

\section{METODOLOGÍA}

El objetivo de la investigación documental es analizar la información escrita sobre un determinado tema, con el propósito de establecer relaciones, diferencias, etapas, posturas o estado actual del conocimiento respecto del tema objeto de estudio. En consecuencia, esta investigación es de tipo histórico y documental, porque su objetivo es estudiar los sucesos del pasado, analizar la relación de dichos acontecimientos con otros eventos de la época y con sucesos presentes; en síntesis, buscar entender el pasado y su relación con el presente y futuro.

El presente trabajo consta de tres etapas:

1. Búsqueda de bibliografía, recolección y organización de datos.

2. Investigar aspectos doctrinarios de las diversas legislaciones europeas e históricas referentes a este mecanismo y analizar los principios procesales establecidos en la Constitución de la Republica hondureña y en el Código Procesal Civil hondureño.

${ }^{4}$ El artículo 676 del $\mathrm{CPCH}$ establece que el proceso monitorio será el adecuado para la interposición de pretensiones cuyo fin sea únicamente el pago de una deuda de dinero, vencida y exigible, de cantidad determinada en lempiras o en monedas extranjera admisible legalmente, hasta un límite de doscientos mil lempiras (L. 200, 000.00). 
3. Traducir al idioma español los parágrafos 688 al 703 del Código Procesal Civil alemán (Die Deutshe Zivilprozessordnung, ZPO); los artículos 1405 al 1425 del Código Procesal francés (Code de Procédure Civile) y los artículos 633 al 656 del Código de Procedimientos Civiles italiano (Codice di Procedura Civile); con la finalidad de estudiarlos y compararlos con los artículos 812 al 818 de la Ley de Enjuiciamientos Civiles española y los artículos 676 al 683 del Código Procesal Civil hondureño; todos referentes al proceso monitorio.

\section{OBJETIVOS}

Objetivos generales

1. Crear un instrumento de consulta cuyas fuentes se obtendrán mediante el estudio del derecho procesal comparado europeo con relación al hondureño.

2. Determinar si mediante la ejecución derivada de la inacción del deudor, se violentan las garantías procesales del mismo.

\section{Objetivos específicos}

1. Investigar sobre los antecedentes históricos de este mecanismo de reclamación de deudas dinerarias.

2. Definir el término procedimiento monitorio.

3. Indagar cuáles son las formas monitorias existentes.

4. Determinar cuál es la naturaleza jurídica del proceso monitorio hondureño.

5. Equiparar el proceso monitorio hondureño con el alemán, francés, italiano y español.

\section{CAPÍTULO I. ANTECEDENTES HISTÓRICOS}

\section{Antecedentes del juicio ejecutivo}

El derecho procesal de occidente tiene sus orígenes en el derecho romano, germano y canónico; sin embargo, dependiendo de cuál de esos derechos se destaque, así serán las características dominantes de las normas procesales actuales. Nuestro juicio ejecutivo de raíz hispánica deriva del processus executivus, teniendo, por tanto, sus antecedentes en la legislación romana y en la legislación germana. 


\section{Derecho romano}

En el procedimiento de las acciones de la ley, vencido el plazo de treinta (30) días (tempus iudicati) sin que el deudor condenado cumpliera con la obligación impuesta, el acreedor, previa solicitud al magistrado, estaba facultado para tomar posesión de la persona del deudor. En un periodo posterior, durante la vigencia del proceso de formulario, una ley poetelia, se elimina la prisión por deudas y transcurrido el tempus iudicati, el actor debía ejercitar el actio iudicati, la cual consistía en una nueva acción que nacía de la sentencia misma y que consistía en un nuevo proceso de conocimiento tendiente a obtener el cumplimiento de la misma.

En el derecho romano en ninguna de sus etapas históricas se conoce la ejecución de sentencia, mucho menos el proceso ejecutivo, solamente existió el proceso ordinario.

\section{Derecho germano}

Primigeniamente en el derecho germano, al considerarse el incumplimiento de la sentencia, una injuria, el acreedor estaba facultado para ejecutarla en forma privada. Pero, en un edicto de Teodorico y de la legislación carolingia, se elimina la ejecución directa, debiendo solicitarse al juez las medidas pertinentes, siendo él quien las ordenaría sin ninguna clase de conocimiento. El conocimiento, donde el deudor podría plantear sus defensas, tendría lugar con posterioridad a la ejecución.

\section{La fusión del derecho romano y germano}

A partir del siglo XI, de la fusión de ambos derechos, surge el proceso común u ordinario, en el que los principios fundamentales sobre prueba y sentencia fueron romanos y de la tradición germánica se toma la división del proceso en dos periodos, uno anterior y otro posterior a la contestación de la demanda, la división del procedimiento en diversas etapas con términos diferentes y un orden de las pruebas legales, dándole al proceso su extensión actual y su compleja estructura.

También de la fusión de ambos derechos nace el proceso ejecutivo, que tiene una etapa de conocimiento por herencia romana y una limitación de las defensas por la influencia germana; de esta manera, se pueden plantear oposiciones o defensas posteriores a la sentencia.

Primero se van a ejecutar las sentencias de los procesos de conocimiento y posteriormente a la sentencia se agregan los instrumenta guarentigiata que, 
otorgados ante un notario, tenían una cláusula mediante la cual el deudor se comprometía a pagar una obligación reconocida en el mismo instrumento. ${ }^{5}$ Por el principio de que el confeso era equiparable al condenado, se asimilan estos instrumentos a sentencia, con la oposición, beneficio que luego se acuerda a las letras de cambio, siendo estos los orígenes del processus executivus.

\section{Antecedentes del proceso monitorio}

La mayoría de las investigaciones realizadas sobre este tema señalan que fue en la alta Edad Media italiana donde surge este procedimiento, en el siglo XIII; período en el cual se vivió en la Península Itálica un importante resurgir del comercio, como consecuencia del gran número de transacciones comerciales de los mercaderes italianos que se daban dentro y fuera de sus límites geográficos, surgiendo así la necesidad de regular un procedimiento sencillo, ágil y eficaz, que fuera capaz de superar la extrema lentitud y onerosidad del procedimiento ordinario de aquel entonces (solemnis ordo iudiciarius). Para superar dicho problema, en este contexto nació, en ese mismo siglo, el preceptum o mandatum de solvento cum cláusula instificativa, base del actual proceso monitorio.

De acuerdo a Gutiérrez Alviz y Conradi, ${ }^{6}$ el proceso se iniciaba con un mandato del juez que disponía parar o hacer alguna cosa (de solvendo vel trahendo), pero esta orden o mandato venía emanada sin una previa cognición (ante causa cognitionem). Las posibles objeciones a la admisibilidad del preceptum o mandatum derivadas de la falta de cognición previa, venían resueltas con la justificación de que el proceso recibe de la cláusula que en él contiene (si sennseris reus te gravatum, compareas coram nobis complementum institioe receptuturus). En razón de esta cláusula, el curso del procedimiento podía llegar a dos resultados opuestos: o el deudor intimado no comparecía, entonces el mandato se confirmaba pasando en autoridad de cosa juzgada; o bien el deudor comparecía, entonces su sola comparecencia hacía que el procedimiento especial cesara, teniéndose que seguir los trámites del juicio ordinario.

Al respecto, Chiovenda ${ }^{7}$ señala que el proceso monitorio, o de apremio, se estableció en el derecho medieval italiano mediante el mandatum de solvendo, por el uso de no citar a juicio al deudor, sino de obtener directamente del juez la orden que abría la ejecución acompañada de la cláusula justificativa, que permitía al

\footnotetext{
${ }^{5}$ En la actualidad es el equivalente a la deuda reconocida en instrumento público (art. 782.1, CPCH).

${ }^{6}$ GutiérrezAlviz, F. y Conradi. (1972). El procedimiento monitorio: estudio de derecho comparado. Sevilla.

${ }^{7}$ Chiovenda, G. (1949). Las formas en la defensa judicial del derecho. En Ensayos de derecho procesal civil. BuenosAires: Ediciones E. He.A.
} 
deudor que quisiera hacer valer excepciones, que formulara oposición dentro de determinado término y que se distinguía del mandato de solvendo del processus executivus o sine cláusula porque este debía llevarse a cabo a pesar de existir oposición.

Este proceso se expandió al derecho germano entre los siglos XIV y XVI, reelaborando este proceso a la luz de principios informadores que reglan su ordenamiento jurídico. Fueron precisamente ellos quienes alcanzaron resultados más seguros y convincentes, logrando consolidar definitivamente este proceso especial en Europa. Así, el Mahnverfahren alemán o el Mandatsverfahren austriaco, surgieron producto de una depurada técnica legislativa que se consolidaría firmemente de la praxis de los tribunales civiles. Mientras, en Italia, el viejo preceptum o mandatum de solvendo cum cláusula iustificativa no arraigaría en el diario quehacer profesional de los prácticos y sería objeto de múltiples y diseminadas disposiciones normativas que no recogerían un texto articulado aplicable con carácter general a todo tipo de supuestos, sino meras aplicaciones parciales de este proceso.

\section{Antecedentes del proceso monitorio en otros paises europeos}

1. Italia: Aunque Italia se presenta para la mayoría de los autores como la cuna del proceso monitorio, citado en sus orígenes medievales a través del mandatum de solvendo cum clausula iustificativa, esta posibilidad sumarial desapareció por influjo del derecho francés, hasta que en 1922 se publica la Ley 1035, que desarrollada por el Decreto 1036 del 24 de julio de 1922, dio origen de nuevo al procedimento d'ingiunzione. En 1936 fue reformada e introducida posteriormente en el Codice di Procedura Civile del 28 de octubre de 1940, en sus artículos 633 al 656.

2. España: En las fuentes legales castellanas (del siglo XV al XVI) no se encuentran antecedentes que recojan el proceso monitorio italiano, asimismo no hay literatura alguna de la época; sino hasta finales del siglo XVII y principios del XVIII. Es hasta en 1974 que comienza a tratarse el concepto del proceso monitorio, a fin de darle la agilidad necesaria a todas aquellas reclamaciones dinerarias pequeñas, para desahogar la estructura del proceso ejecutivo. Se dice que esta es una figura nueva en apariencia, según se trata, pero en la Ley de Propiedad Horizontal, en su artículo 17, aparece regulado dicho proceso. Esta Ley fue creada en 1960 para la reclamación proveniente de todas aquellas obligaciones que generan la ocupación de un piso 0 apartamento, pero fue hasta en el año 2000 que se crea la Ley de Enjuiciamiento Civil, que en su artículo 812 estructura dicho proceso para la reclamación de deudas dinerarias. 
3. Francia: A pesar de que la región de Alsacia contaba con un proceso de commandement de payer por su incorporación al Reich ${ }^{8}$ en 1871, al asumir la legislación de su ordenación de leyes procesales civiles que continuó vigente hasta principio de 1882, es a partir de un decreto de 1937 y su posterior reforma en 1953, cuando comienza su arraigo a nivel nacional. Mediante una reforma en 1957 se separaron los procesos monitorios para la reclamación de deudas civiles de las deudas comerciales. Posteriormente, en 1972, se produciría una gran reforma del procedimiento, eliminando las limitaciones cuantitativas de la reclamación, para en 1981 volverse a reformar designándose a los huissiers de justice como los encargados de las notificaciones y sentando las cuestiones ambiguas de la anterior regulación, siendo el procedimiento definitivo que actualmente recoge el Nouveau Code de Procédure Civile.

4. Alemania: La República Federal de Alemania incorpora esta figura procesal en su código civil del 30 de enero de 1877, pero que en 1909 sufre una transformación radical, configurándose el Mahverfahren, que incorporaba la no necesidad de acompañar ab initio documento alguno, como sucedía con su precedente mandatum de solvendo. En 1957 se dispone su tramitación por un Rechspfleger o auxiliar de justicia, con el fin de liberar a los jueces de tramitaciones rutinarias que se estimaban como las causantes del atasco de los tribunales. Pero, es en la reforma de 1976 cuando se introducen en este instituto procesal relevantes novedades que afectaban a la simplificación del procedimiento, al asentamiento de las bases para un posterior tratamiento informático del proceso y se amplía su ámbito territorial para servir de título ejecutable fuera de Alemania al amparo del Convenio de Bruselas. Posteriormente, también se han dado otras pequeñas reformas procesales tendentes a la agilización de este proceso.

5. Austria: El ordenamiento jurídico austríaco cuenta, al igual que la República Federal de Alemania, con un proceso monitorio "puro", plasmado en la Ley de 1873 y regulada en los parágrafos 548 al 559. De acuerdo con la misma, en virtud de la simple petición escrita u oral del acreedor, en la cual el juez competente libra una orden de pago sin audiencia del deudor, con advertencia a este que puede oponerse dentro de los catorce días de la notificación. Si el deudor no se opone en el término mencionado, la orden de pago se hace ejecutiva sin otro remedio procesal que la restitución; pero, cuando el deudor pruebe que no pudo oponerse

\footnotetext{
${ }^{8}$ El Imperio Alemán (en alemán: Deutsches Reich, llamado por algunos historiadores alemanes o simplemente Kaiserreich) se refiere a Alemania desde su unificación y la proclamación de Guillermo I como emperador, el 18 de enero de1871, hasta 1918, cuando se convirtió en una república después de su derrota en la Primera Guerra Mundial y la abdicación de Guillermo II (9 de noviembre de 1918).
} 
por suceso imprevisto o inevitable, aún sin aducir los motivos, basta formular la oposición para hacerle perder su fuerza ejecutiva a la orden de pago.

\section{CAPÍTULO II. MARCO CONCEPTUAL}

El término monitorio, según el Diccionario de la Real Academia Española, deriva del latín monitorius y es un adjetivo cuyo significado es "que sirve para avisar 0 amonestar." En el derecho europeo se ha utilizado indistintamente los términos monitorio o inyunción; así, es español tiene el sentido de: advertencia, apercibimiento 0 requerimiento que se dirige a una persona (en este caso, al deudor para que pague. En cuanto a la palabra inyunción, esta no figura en el Diccionario de la Lengua Española, pero sí aparece el verbo inyungir, derivado del verbo latino iniungere, que significa: "mandar, prevenir, imponer".

Correa Delcasso (1998) define el proceso monitorio como: "Aquel proceso especial plenario rápido que tiende, mediante la inversión de la iniciación del contradictorio, a la rápida creación de un título ejecutivo con efectos de cosa juzgada en aquellos casos que determina la ley". ${ }^{\circ}$

Pérez Ragone (2006) manifiesta que por la variedad de formas existentes, conceptualizar al proceso monitorio no es fácil, ya que históricamente en el derecho comparado europeo actual existen y coexisten variedades de formas monitorias que pueden ser consideradas de la siguiente manera: modelos bases de tradición monitoria (Alemania e Italia), modelos bases derivados (Suiza y Austria), modelo de recepción tardía (Bélgica, Francia, Grecia, Portugal, España, Luxemburgo), modelos con procesos similares que tienen función monitoria (Países Escandinavos, Gran Bretaña, Holanda).

En conclusión, conviene mejor hablar de formas monitorias, las que permiten una mejor descripción sobre la base de la estructura, técnica y objetivos de la monición, ${ }^{10}$ sin insuficiencias o errores conceptuales. Describiéndolas de la siguiente manera: "Las formas monitorias pertenecen a los procesos simplificados que tienen por objetivo el otorgamiento de un título ejecutivo judicial (sentencia monitoria) en forma rápida, económica y con escasa participación del órgano jurisdiccional; mediante una previa intimación de pago judicial (aviso de pago 0 requerimiento de pago), contra la cual el requerido no ofrece oposición oportuna y suficiente (técnica del secundum eventum contradictionis); solo en caso de

${ }^{9}$ Correa Delcasso, Juan Pablo. El proceso monitorio en la nueva Ley de Enjuiciamiento Civil. La Ley 1998-2. pp.1902.

${ }^{10}$ Del lat. monitĩo, -ōnis, advertencia que se hace a alguien. 
oposición pesa sobre el requirente instar el proceso contradictorio de conocimiento (estructura de la inversión del contencioso)".

\section{Marco legal actual}

En principio, en los procedimientos declarativos se sustancia el proceso de conocimiento en el mismo, en el que se deben distinguir dos momentos; en primer lugar, la discusión o debate de la cuestión objeto del litigio y, luego de la discusión, se dicta la sentencia definitiva que contiene la declaración de certeza del derecho y, en su caso, la condena al demandado viene a ser el título ejecutorio que abre las puertas para la ejecución forzosa. En una etapa ulterior, en el supuesto que el demandado no cumpla voluntariamente con la condena que se le ha impuesto en esa sentencia, se tramita el proceso de ejecución.

En el proceso monitorio las cosas ocurren de otra manera porque se invierten los momentos de la discusión y de la resolución: el juez, frente a la demanda del actor, dicta en primer lugar y sin previa contradicción la sentencia monitoria ordenando al demandado el cumplimiento de una determinada prestación, luego en una etapa ulterior, concede al demandado la oportunidad para que formule su oposición, fijándole un plazo a tales efectos. Es decir, se desplaza la iniciativa del contradictorio al demandado, en cuanto este último debe formular la oposición para enervar los efectos de la sentencia monitoria favorable al accionante. La oposición del demandado presenta distintos requisitos y también son distintos los efectos, según se trate del proceso monitorio puro o del proceso monitorio documental y la forma en que se encuentren legislados en cada ordenamiento.

\section{CAPÍTULO III. CLASIFICACIÓN DE LAS FORMAS MONITORIAS}

\section{Proceso monitorio ejecutivo y de conocimiento}

En palabras del profesor Pérez Ragone, a esta estructura se le conoce como "preparación de la vía ejecutiva", ${ }^{11}$ y lo que pretende es que el requirente solo desee contar con un título que habilite la ejecución. $\mathrm{O}$ sea, que el resultado fundado en la falta de reacción del requerido justifica una sentencia que dé un título ejecutivo, es decir, una sentencia condenatoria que permita que se lleve a cabo la ejecución de la misma. Pero, en caso de oposición del requerido, se abre la posibilidad para que el

11 Pérez Ragone, Á. (Julio de 2006). En torno al procedimiento monitorio desde el derecho comparado europeo: caracterización, elementos esenciales y accidentales. Revista de Derecho, Valdivia, (XIX), 1, pp. 205-235. 
acreedor dé instancia a un proceso de conocimiento contradictorio, en el cual la fase monitoria sirve como una introductoria a este. ${ }^{12}$

\section{Proceso monitorio documental y puro}

La doctrina italiana desarrolló desde el medioevo la distinción entre proceso documental, que incluía al monitorio documental, y la ejecución de títulos no judiciales (proceso executivus) y no documentales, en donde las diversas regulaciones procedimentales en la actualidad suelen dividirse, básicamente, en dos grandes grupos:

1. Engloba aquellos ordenamientos jurídicos (básicamente del norte y del centro de Europa) que regulan un proceso monitorio en el que no se requiere, para su puesta en funcionamiento, de un principio de prueba documental por escrito que acredite la legitimidad de la deuda reclamada por el acreedor y que, siguiendo con la terminología acuñada por Calamandrei a principios de siglo, puede calificarse de proceso monitorio"puro, porque es el que más se asemeja al histórico mandatum de solvendo cum clausula iustificativa del cual procede.

2. El segundo grupo incluye aquellos otros procedimientos monitorios latinos (como ahora el francés, el italiano, el portugués o el juicio monitorio español) en los que se exige que a toda demanda o petición monitoria se acompañe un principio de prueba documental por escrito, denominados, por este mismo motivo, procesos monitorios de tipo documental.

\section{CAPÍTULO IV. NATURALEZA JURÍDICA DEL PROCESO MONITORIO HONDUREÑO}

El proceso monitorio hondureño reviste una naturaleza jurídica mixta, al tener tanto manifestaciones del proceso declarativo como del ejecutivo. La primera etapa que comienza desde la admisión de la petición monitoria hasta la constatación del impago o la oposición del deudor, reviste una naturaleza jurídica declarativa especial.

La segunda etapa se desdobla en dos posibilidades: en el primer caso, si el deudor se opone al requerimiento de pago, la segunda etapa iniciaría con la convocatoria de

\footnotetext{
${ }^{12}$ Pérez Ragone... op cit., pp. 210.
} 
la audiencia si la cuantía no excede del proceso abreviado o con la presentación de la demanda ordinaria si excede de dicha cuantía; en este caso, el proceso monitorio conserva la naturaleza declarativa de la primera etapa, pero ya no especial, sino declarativa ordinaria. ${ }^{13}$ La segunda posibilidad plantea el caso del impago o silencio del deudor, en la cual la segunda etapa inicia con el despacho de la ejecución hasta la satisfacción del derecho del acreedor, ante esta posibilidad la segunda etapa del monitorio reviste naturaleza ejecutiva.

Asimismo, el procedimiento monitorio hondureño es del tipo documentado, ya que para su admisión el artículo 680 del CPCH exige justificación documental de la deuda vencida, líquida y exigible y que dichos documentos sean de los previstos en el artículo 677 del CPCH o que constituyeren a juicio del juez un principio de prueba. Sin esta valoración se discriminaría al deudor, a quien el legislador, una vez incoado el proceso monitorio, coloca en una posición procesal generadora de obligaciones para el mismo.

\section{CONCLUSIONES}

El Código Procesal Civil hondureño establece los mecanismos de comunicación para garantizar un juicio sin indefensión (artículos 135-150); asimismo, el artículo 680 del mismo cuerpo legal establece que se requerirá mediante providencia al deudor, para que en un plazo de 20 días pague al peticionario o se oponga; relacionando este articulo con el 124.1: "Los plazos comenzarán a correr desde el día siguiente a aquel en que se hubiere efectuado a cada interesado el acto de comunicación del que la ley haga depender el inicio del cómputo y se contará en ellos el día del vencimiento, que expirará a medianoche". Por lo que en ningún momento se violenta el derecho a la defensa al deudor, ni se le impide el acceso a la justicia; esta técnica lo que pretende es procurar celeridad al proceso procesal, economía procesal; como consecuencia del impago e inacción del deudor, se procede a ordenar la ejecución. De igual manera, el código da una opción más al deudor, ya ordenada la ejecución en esa instancia, se le permite presentar oposición como lo establece el artículo 682.1: "Ordenada la ejecución, proseguirá esta conforme a lo dispuesto en el capítulo IV, título II, libro VI, de este Código, pudiendo formularse la oposición prevista en estos casos, pero el demandante del proceso monitorio y el

\footnotetext{
${ }^{13}$ Si la cuantía original o la resultante de la aceptación parcial del reclamo por parte del deudor no fuere superior a cincuenta mil lempiras (L.50,000.00), el juzgado procederá de inmediato a convocar a las partes a la audiencia (Art. 588), obviándose la demanda o el formulario normalizado con que generalmente se inicia el proceso abreviado. cuando el importe de la reclamación o el saldo no pagado exceda de cincuenta mil lempiras (L.50, 000.00), el acreedor deberá interponer una nueva demanda dentro del plazo de un mes, contado desde la entrega de la copia del escrito de oposición.
} 
deudor ejecutado no podrán pretender ulteriormente en un proceso ordinario 0 abreviado la cantidad reclamada en el monitorio o la devolución de la que con la ejecución se obtuviere".

La técnica monitoria debe respetar determinados parámetros para que se resguarde el debido proceso, principalmente la notificación fehaciente, la comunicación adecuada al requerido advirtiendo sobre las consecuencias de su inacción en determinado plazo y facilitarle la contestación como la realización del acto de oposición. El derecho de defensa se garantiza brindando la oportunidad para ser oído y oponerse, de modo que tampoco habría objeciones desde el debido proceso para impedir que esa orden de pago y el silencio del requerido justifiquen la resolución monitoria de ejecución, inmediatamente o en forma diferida.

Desde la aparición del proceso monitorio en la Edad Media, surgiendo como el mecanismo más eficaz para la resolución de controversias de carácter civil y mercantil, gracias a la reducción de trámites y a la menor exigencia de requisitos formales, este proceso ha evolucionado y ha sido adaptado a diversos ordenamientos jurídicos europeos y del continente americano, por lo que el derecho comparado brinda una mejor diferenciación y entendimiento de las formas monitorias existentes en la actualidad.

En síntesis, la creación de este instrumento de consulta permitirá una mejor visión y, en consecuencia, una mejor aplicación de este mecanismo. Asimismo, dará apertura a futuros estudios del procedimiento hondureño con diversas legislaciones, sin limitarse a este procedimiento, y de esta forma crear un instrumento de carácter general.

\section{AGRADECIMIENTOS}

Al abogado César Andrés Velásquez Moncada, por el apoyo brindado en mi proyecto de tesis y por elegir mi trabajo para la presente publicación; a mi maestra de alemán, Sarina Sinke, y al abogado Kathrin Rothe, por ayudarme a obtener información relativa a la legislación alemana, a la licenciada Mirta Macías Ruano, coordinadora regional de Investigación Científica UNAH-VS, por el apoyo en la edición de este trabajo para su respectiva publicación. 


\section{BIBLIOGRAFIA}

Calvinho, Gustav. (2006). Debido proceso y procedimiento monitorio. En El debido proceso. Buenos Aires: Editorial Ediar.

Chiovenda, G. (1949). Las formas en la defensa judicial del derecho. En Ensayos de derecho procesal civil. BuenosAires: Ediciones E. He.A.

Comisión de las Comunidades Europeas. (2002). Libro verde sobre el proceso monitorio europeo y las medidas para simplificar y acelerar los litigios de escasa cuantía. Bruselas.

Corte Suprema de Justicia. Código Procesal Civil Hondureño Comentado (comentarios de la abogada Edith Urtecho López), pp. 826 - 834.

Correa Delcasso, Juan Pablo. (1998). El proceso monitorio en la nueva Ley de Enjuiciamiento Civil. La Ley 1998-2. pp. 1902 y s.s.

Correa Delcasso, Juan Pablo. (1998). El procedimiento monitorio. Barcelona: Ed. Bosch.

Gutiérrez Alviz, F. y Conradi. (1972). El procedimiento monitorio: estudio de derecho comparado. Sevilla.

Guzmán Fluja, Vicente C. y Espinosa de los Monteros, Rocío Zafra. (2008). Comentarios prácticos a la Ley de Enjuiciamiento Civil. Barcelona.

Instituto Iberoamericano de Derecho Procesal. (1988). Texto de anteproyecto del Código Procesal Civil Modelo para Iberoamérica. Montevideo.

Pérez Ragone, Álvaro. (Julio de 2006). En torno al procedimiento monitorio desde el derecho comparado europeo: caracterización, elementos esenciales y accidentales. Revista de Derecho, Valdivia, (XIX), 1, pp. 205-235.

Tomás y Valiente, F. (1960). Estudio histórico-jurídico del proceso monitorio. Revista Derecho Procesal, pp. 33 yss. 